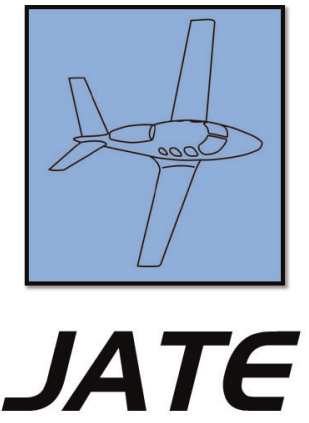

Journal of Aviation Technology and Engineering 10:2 (2021) 1-15

\title{
Female Relief Systems in U.S. Military Fighter Ejection Seat Aircraft
}

\author{
Marian C. Schultz ${ }^{1}$ James T. Schultz ${ }^{2}$, and Joshua J. Schultz ${ }^{3}$ \\ ${ }^{1}$ The University of West Florida \\ ${ }^{2}$ Capitol Technology University \\ ${ }^{3}$ L3/HARRIS Technologies Corporation
}

\begin{abstract}
In early aircraft, the amount of fuel the aircraft could carry usually determined how long it could stay in flight. Today, with aircraft being able to air refuel, the time they are able to stay aloft is based more on human needs, one being waste management. Voiding urine in a single-seat ejection seat aircraft has been an issue for male pilots in the past, but with the increasing numbers of female pilots in singleseat aircraft, finding a solution has intensified. This paper reviews the various methods that are available for both male and female pilots, including the newest method which allows the pilot to vacuum urine into a containment vessel. Future improvements in waste management will continue to progress with time and technology. While these may involve improving ways to urinate in the cockpit, they could also involve ways to perhaps slow the production of urine by the body. But for the present, pilots will have to select from a pool of the devices currently available.
\end{abstract}

Keywords: aviation urination, female aviation and urination, ejection seat urination, urination in flight, piddle packs, AMXD

Adequate hydration, along with the subsequent elimination of urine during flight, has long been the bane of the fighter pilot community. While the earliest aircraft took to the skies for the briefest of sorties, ever since aircraft could stay aloft longer than humans were able to retain urine without voiding, there has been a need to solve the problems associated with in-flight bladder relief. For safety purposes, bladder relief should be achievable without having to unbuckle or loosen ejection seat straps. Under normal hydration, the body produces approximately $100 \mathrm{~mL}$ of urine per hour; the impulse to void is typically initiated when approximately $200 \mathrm{~mL}$ of urine accumulates in the bladder over a two-to-four-hour period (Dugdale, 2019). To avoid urination in flight, aircrew members have been known to intentionally dehydrate themselves prior to long missions (Werfelman, 2008). However, dehydration is especially hazardous for aircrew since it can reduce G-force tolerance levels experienced in high-performance flight and intensify the threat of G-induced loss of consciousness (The Possibility of G-Induced Loss of Consciousness, 1988). Chronic dehydration leads to impairments in cognitive flight performance, spatial cognition, and short-term memory (Lindseth et al., 2013), and poses long-term urological, gastrointestinal, circulatory, and neurological risks (El-Sharkawy et al., 2015). The latest technology developed under contract with the Air Force and Navy provides a safe, sanitary, and automated solution for in-flight bladder relief.

This descriptive study examines the various methods currently available to pilots in order to void urine in flight. Approximately 35 female pilots were interviewed for this study over a 24-month period. Participation in the study and interview was agreed to as long as anonymity was guaranteed. 


\section{History of Urination in Flight}

While there have been significant changes in aviation technology, the basic issues underlying urination while in flight went unsolved during the first century of manned flight. Commodes are available in larger aircraft, while other options to manually relieve oneself in aircraft without a toilet include piddle-packs, containers, and plastic bags. With advanced technology, aircrew automatic bladder relief and collection systems are available (Mizokami, 2019).

When hot air balloons were invented, the need to void was resolved by evacuating over the side of the balloon, or by voiding into a container reserved for waste material (Figure 1). During World War II, the military endeavored to resolve this urinary basic necessity by providing a relief

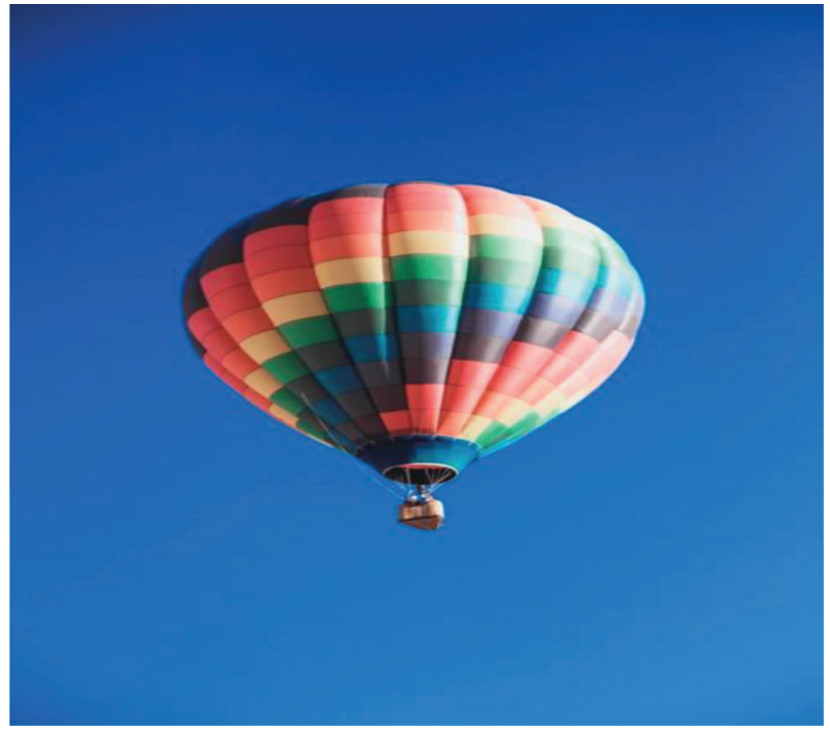

Figure 1. Hot air balloon. (2021. Unsplash, https://unsplash.com/s/photos/ hot-air-balloon) tube in the cockpit of aircraft such as the P-40 (Figure 2). While the majority of military combat pilots were male, there was still a concern that urine would corrode the metal aircraft frame.

"Horn and valve" systems were rudimentary, allowing a male pilot to partially disrobe and relieve himself into the horn. Pulling the lever would activate the valve, allowing the waste to be released from the underside of the aircraft. Although this type of process was considered quite basic, they remained in use throughout the Cold War (Figure 4).

Current fighter aircraft were designed during the Cold War specifically to engage and defeat the Soviet Union in the skies over Europe and the Pacific. These aircraft were primarily designed for short missions flown relatively close to home base in defense of the USA and its NATO allies. Since the end of the Cold War, and particularly since the advent of the Global War on Terror, the United States has employed fighter aircraft in very remote regions of the world. This factor, combined with in-flight refueling that allows for extended flight durations, possibly up to five times longer than the original designers envisioned, has exacerbated the need for in-flight relief. Pilots continue to be confronted by this human factor challenge that requires monitoring waste management o these longer missions. These challenges, if not adequately addressed, can have a dramatic impact on combat effectiveness, mission safety, and military preparedness for fighter aircrew. Disrobing to prepare for horn and valve relief is no longer viable with modern flight suits and, even if it was, horn and valve systems were designed in an era in which males dominated the field of tactical flight. Female pilots have had limited tools for in-flight relief since they joined fighter pilot missions in 1993.

The United States currently operates and employs seven primary fighter/attack aircraft throughout the Air Force, Navy, and Marines. These aircraft include: F-15 Eagle and

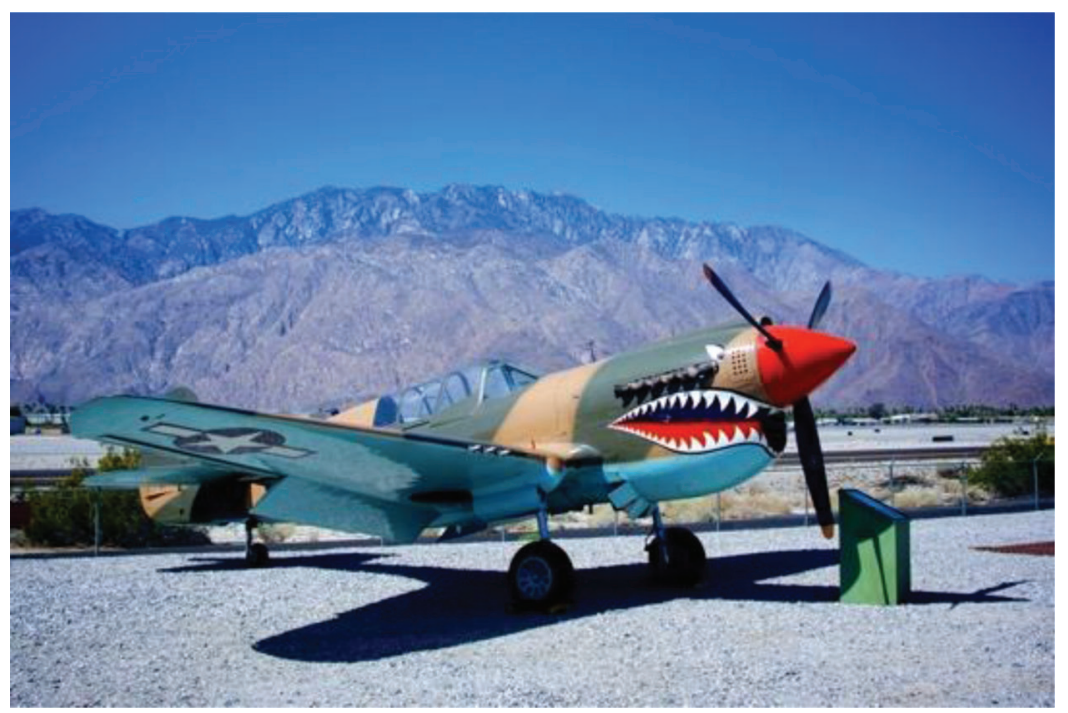

Figure 2. P-40 Tomahawk with flying tiger markings. (2021. Public Domain, https://www.publicdomainpictures.net/pictures/100000/velka/p-40-warhawkfighter.jpg) 


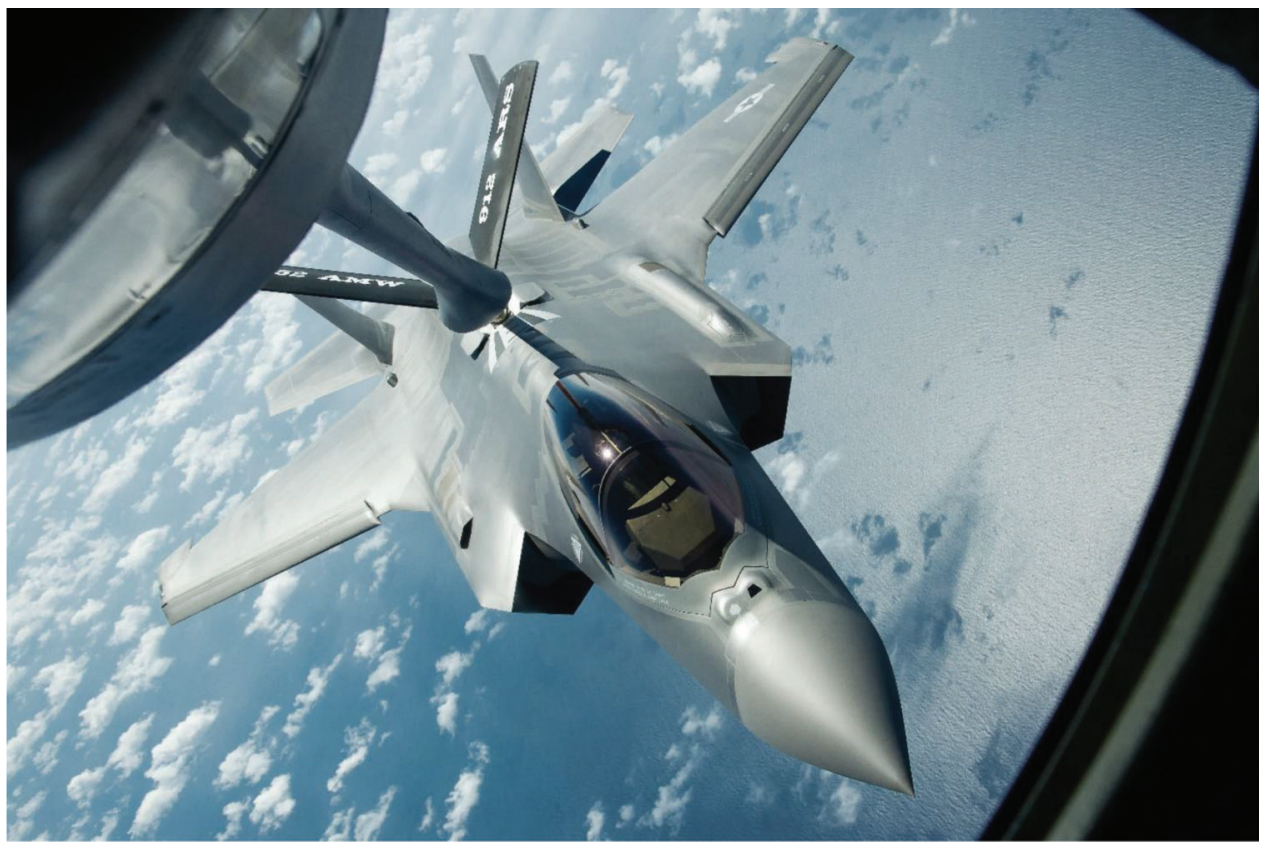

Figure 3. An F-35A Lightning II approaches a KC-135 Stratotanker during aerial refueling May 13, 2013. (U.S. Air Force photo/Master Sgt. John Nimmo.)

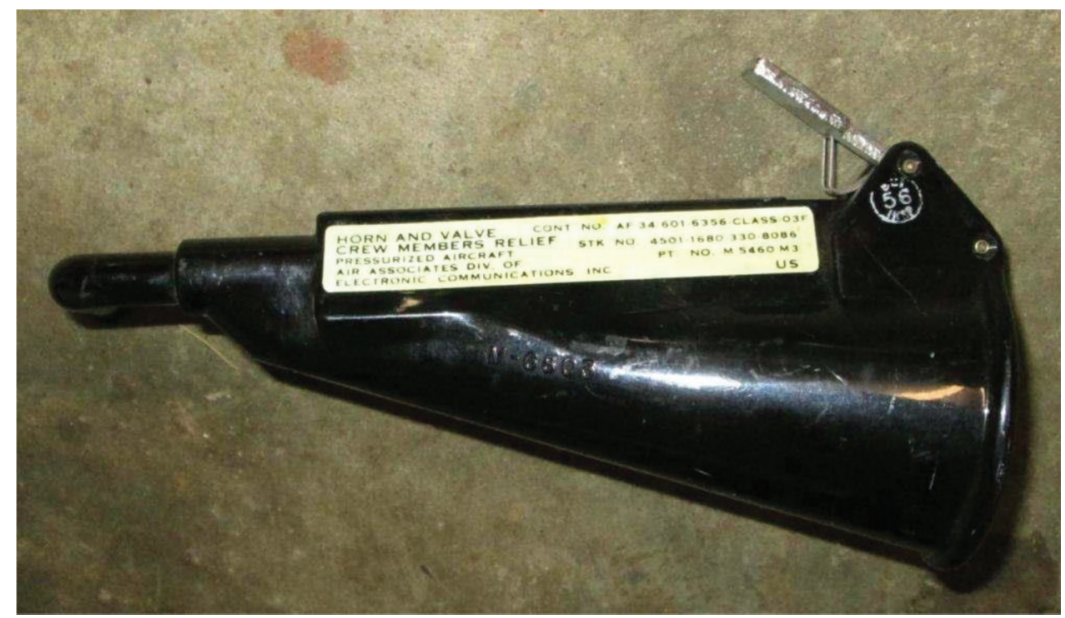

Figure 4. "Horn and valve" system designed for pressurized aircraft. (Horn and valve for crew members relief. (2017). U.S. Air Force photo. https:// www.google.com/search?q=pilot\%20relief\%20tube\%20aircraft\&tbm =isch\&hl=en\&sa=X\&ved=0CB0QtI8BKABqFwoTCJjgg-n2O4CFQAAAAAdA AAAABAH\&biw $=1425 \& b i h=759 \#$ imgrc $=$ UxDwVJ9sKrAXmM)

Strike Eagle, F-16 Falcon, F/A-18 Hornet and Super Hornet, F-22 Raptor, F-35 Lightning II, AV-8B Harrier II, and A-10 Warthog. These aircraft have vastly different capabilities and fulfill varied combat missions. Despite the variations, these aircraft share many common design features with respect to human factors. Cramped cockpits, complex displays, and technologically advanced weapons and defense systems demand high mental workloads, and focus pilots' attention to employ these aircraft effectively.

Most of these aircraft rely on the pilot's ability to take advantage of the aircraft's extreme agility and maneuverability to survive the advancing air-to-air and surface-to-air threats facing American forces. These requirements place pilots under high G-forces and risky physical workloads. With the exception of the F-15 Strike Eagle (Figure 6), certain versions of the Hornet, and training " $D$ " versions of the F-15 and F-16, America's frontline fighters are singleseat aircraft. This ongoing challenge has continued with the development of the F-35, the Joint Strike Fighter for the Air Force, Navy, and Marines (Figure 3).

America currently employs these fighter/attack aircraft in more remote regions of the world with only a few forward operating bases that can be responsible for supporting this limited and difficult access to the battle space. Conflicts in the Middle East have resulted in aircrews flying single-seat missions routinely in excess of 8,9 , and even 10 hours. These longer missions often create unique challenges to aircrew in terms of eating, drinking, and remaining alert to possible attacks, refueling, or mission tasking. A byproduct of these longer missions is that pilots must eat and drink in 
flight to maintain readiness, and subsequently pilots may need to relieve themselves several times throughout a flight.

\section{Ejection Seat Aircraft}

The challenges confronting fighter pilots in relieving themselves during a mission in a single-seat fighter aircraft can be summarized into three general categories. The first category includes the concern for containment, primarily because of the potential for damage to the aircraft. America's fighter/attack cockpits consist of complex ejection seats designed to save the life of a pilot should the aircraft experience a catastrophic malfunction or fatal damage.

Ejection seats are rocket-powered and constructed using sturdy nylon weaves to survive the massive forces experienced during ejection. While the rocket motors, as well as the nylon material, are devised to be water resistant, they may be susceptible to the corrosive nature of urine. Additionally, the ejection seat is situated among several computers, and wire bundles, which are nestled between control devices, performance gauges, and numerous multifunction displays and scopes. If urine leaks between the panels that protect this equipment, it can pool and corrode connection wires and contacts leading to expensive maintenance, or even failure in flight.

The cramped nature of a single-seat fighter cockpit allows little movement throughout a sortie (Figure 5). In order to use a relief bag, pilots must deliberately unbuckle from the ejection seat, position themselves and the bag for use, while maintaining control of the aircraft, and monitoring the flight instruments. Subsequently, the pilot is urinating into a relief bag located directly over the ejection seat and his/her flight suit, G-suit, survival vest, flight gloves, and mission materials. The uncomfortable positions and the possibility of a rushed nature of the effort toward relief can lead to spills, leaks, and misses where the urine does not enter or remain in the intended piddle pack. Urine that is not confined consequently can penetrate the pilot's clothes and seat throughout the remainder of the flight. This discomfort can lead to distractions during critical phases of flight. This uneasy situation can lead to deficient prioritization of critical tasks and lapses in situational awareness and safety during missions.

Accessibility represents the second category of factors facing pilots during the use of relief bags. The forceful changes in aircraft heading, altitude, and attitude created when flying fighter aircraft to maximum capabilities tolerate very little time for pilots to react if the aircraft experiences an emergency. A severe emergency requiring an ejection may result in a calculation of only seconds, or fractions of a second, for the pilot to initiate ejection procedures before the aircraft is in an attitude or altitude that will preclude successful ejection. Situational preparedness is part of every preflight routine and involves putting on a specially designed harness that connects to the ejection seat. This harness has shoulder and leg straps that connect to the parachute that is housed inside the ejection seat. The leg straps are routed underneath the pilot's thighs and through the crotch, connecting on top of the hips. One additional constraint in fighters is a lap belt that straps across the hips of the pilot securing them to the seat in the event of an ejection. With manual bladder relief systems, both male and female pilots must remove both the ejection seat lap belt and the harness leg straps in order to use a piddle pack. The entire relief process can only be accomplished during noncritical phases of flight and requires several minutes from start to

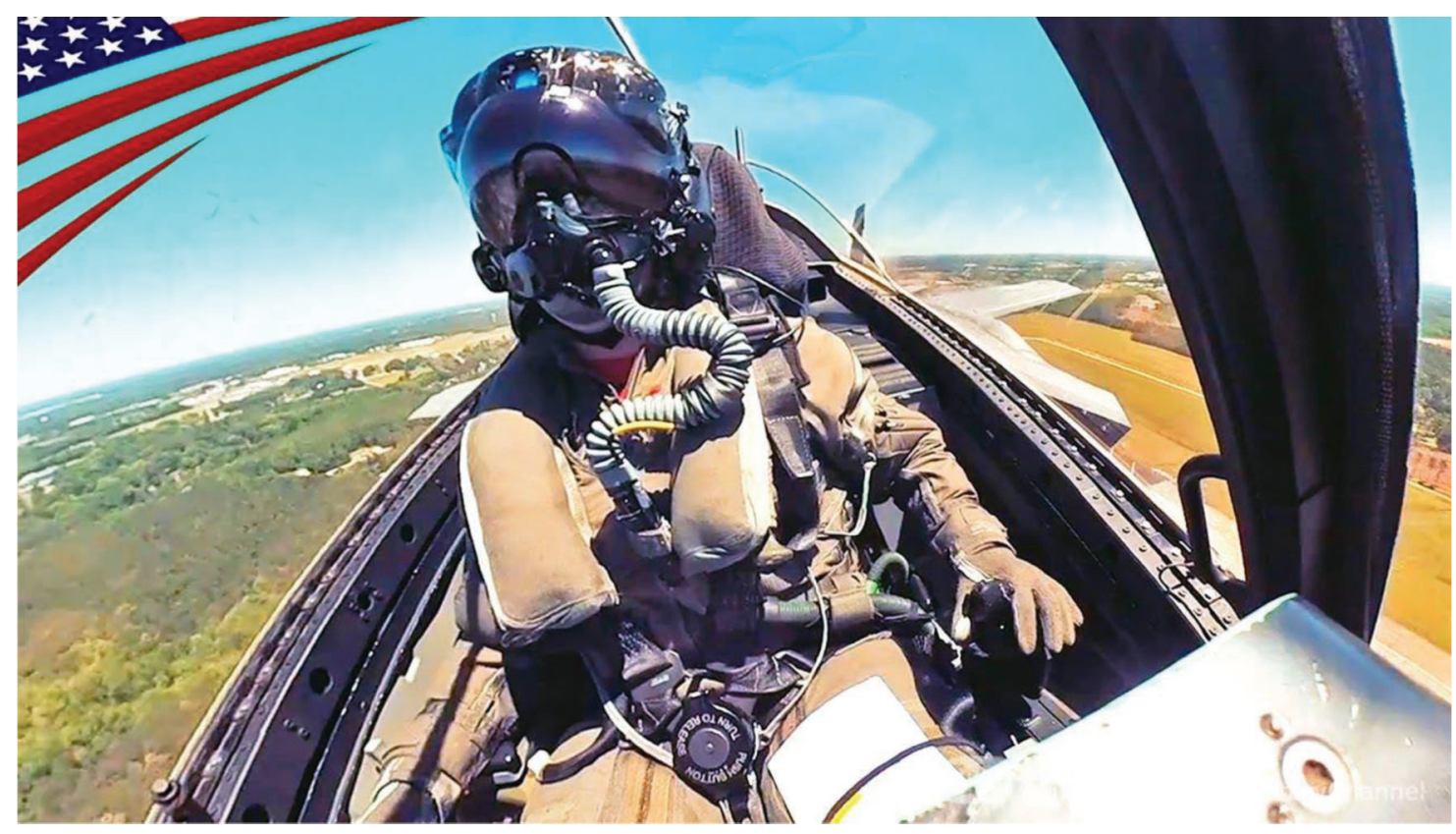

Figure 5. F-35 cockpit view—flyover Manhattan and aerial refueling. (2019, https://www.youtube.com/watch?v=NSLqyhKAhgc) 


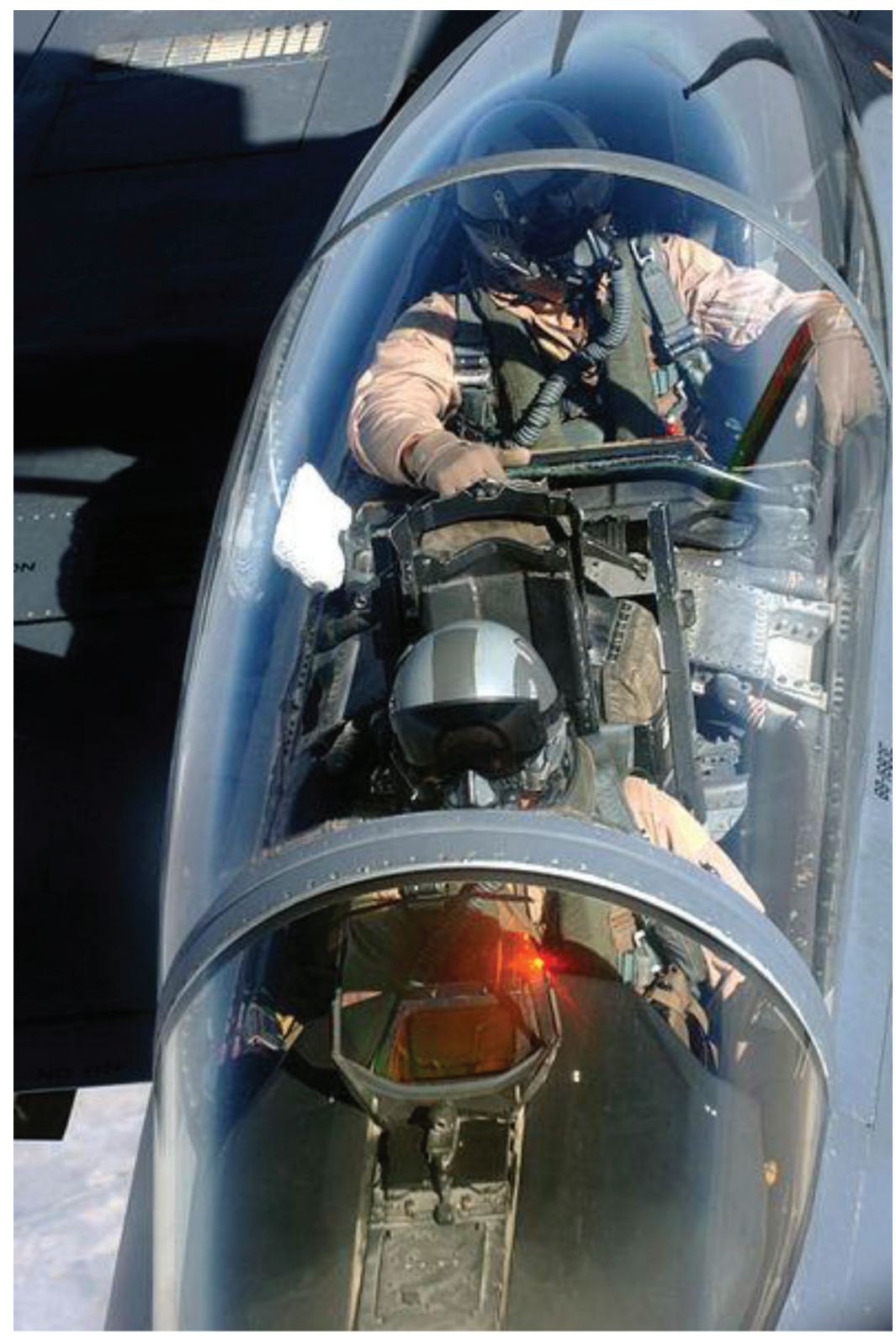

Figure 6. An F-15E Strike Eagle is refueled by a KC-135 Stratotanker, which captures this view of the cockpit. Note the limited maneuverability room provided to its two occupants. (U.S. Air Force photo/SSgt. Joshua Strang, 2016.)

finish. During this time, the pilot is unstrapped from the ejection seat, which poses a major risk in the event of an emergency and necessitates a complete reconnect of the harness for successful ejection.

The third category of challenge to pilots when using relief systems is time. A restrictive factor impacting the employment of fighters is their limited fuel capacity. Today's powerful, maneuverable jets burn fuel at a much higher rate than commercial or transport aircraft. Both training and combat sorties require a plan to optimize fuel consumption to maximize effectiveness. Pilots have only short segments of the flight where they are not actively practicing weapons employment, defensive reactions, or air-to-air engagements. During these high-workload segments of a sortie, it is imp- ractical, risky, and ultimately unsafe for pilots to be actively involved in the relief process. Undoubtedly, the pilot can sufficiently avoid compromising safety, or negatively impacting the mission objective during combat missions only when the task load is sufficiently light to use a relief bag during the air refueling track. A common practice among the fighter community is to train on "hot-pit" sorties which consist of flying a training mission, returning to base, refueling on the ground with the engine(s) running, and, subsequently, flying a second training sortie. These sorties provide ample time for male pilots to use a relief bag, store it appropriately and prepare for the next sortie. Female pilots can take significantly longer to use the current manual relief systems, to the point where many female pilots cannot utilize 
the relief system without extending the period between training sorties, even during a "pit-and-go" operation, 30-45 minutes on the ground.

The three challenges discussed are by no means exhaustive, but characterize the majority of problems facing pilots using a relief system in a single-seat fighter/attack aircraft. Longer training and combat sorties coupled with long deployment flights to foreign countries can lead to the need for pilots to relieve themselves while airborne. Many relief challenges are routinely assuaged by male pilots due to the flexible nature of the male anatomy to conform to several different relief systems in cramped cockpits where there are extreme restrictions on movement. Female pilots contend with the same challenges, but without the flexibility offered to the male anatomy, they are constrained by the need to employ alternate techniques.

\section{Dehydration}

Fighter pilots may implement a tactical dehydration strategy, where pilots will purposely avoid any fluids prior to flying and then ensure that they empty their bladders before they step into the jets to fly a mission (Webster, 2003). While effective, this solution is not practical from a safety or mission effectiveness stance since fighter missions routinely include high-G scenarios and extended aggressive maneuvering. To combat the effects of G-forces on the body, pilots employ the anti-G straining maneuver (AGSM) which involves tightening of the muscles throughout the body to reduce the chances of G-induced loss of consciousness (GLOC). There have been over ten fatal mishaps in fighters due to GLOC, and approximately seven GLOC incidents occur annually, with most resulting in pilots regaining control (Verger, 2020). Dehydration is a major contributing factor to GLOC ("Policy on the Collection and Analysis of Mishap Human Factors Data," 2005). If a pilot must continually maneuver the aircraft while being exposed to high G-forces, the AGSM must be performed each time they maneuver the aircraft. A dehydrated pilot may only be able to accomplish this maneuver half as many times as a pilot who is properly hydrated. Fatigue, another major issue associated with GLOC, impacts effectiveness since many pilots develop a thick layer of sweat during high-G physically demanding maneuvering. A hydrated pilot will not have to work as hard during the AGSM due to higher blood pressure. The cumulative effects of dehydration have real safety concerns, since a pilot who cannot aggressively maneuver the aircraft may be situated in compromising positions while attempting to defend the aircraft (Lindseth et al., 2013). Section 3.5.3 of U.S. Air Force pamphlet 11-419 (United States Air Force, 2014) concludes that proper hydration is critical for normal G-tolerance. Pilots should not wait until a feeling of thirst occurs. Proper hydration starts days, not minutes, before stepping into the aircraft. Pilots should plan to bring sufficient water to the aircraft to meet the demands of unanticipated extended ground ops or high heat conditions.

The F-16 poses a higher level of difficulty in this process because the seat is tilted back at a 30-degree angle. There have been three known F-16 accidents when the pilot was using the piddle pack during flight. The first occurred early in the F-16 program. However, the second and third accidents happened relatively close in time and required safety orders to be issued to F-16 pilots to mitigate any risk of yet another accident. The aforementioned second accident occurred in 1991 over southern California when the pilot disconnected his lap belt and stood on the rudder pedals to lift himself up. The aircraft instantly went into a roll in which the pilot was unable to recover. The third accident happened in Turkey in 1992 when the pilot unstrapped and his lap belt became lodged between the seat and the stick. Both pilots were able to eject from the aircraft safely. Fortunately for both pilots, the parachute is connected to the pilot's harness through separate buckles from the lap belt, which enabled them to eject without injury (Pilots urgent need, 1993). Following these accidents, the Air Force informed pilots that they should only loosen their lap belts, but avoid removing them completely (Bajak, 1993; Chandler, 1991).

Inconvenience is only a small part of the problem facing female fighter pilots regarding relief systems and their utility. One female pilot stated that on pit-and-go missions involving longer air-to-surface missions she would be unable to fully train on the second sortie due to severe bladder discomfort throughout the sortie. Many female pilots have voiced these same concerns showing a possible training inadequacy throughout fighter squadrons. Several female pilots have stated that this issue was one of the driving forces responsible for career choices they have made concerning the choice to continue to fly fighter aircraft. One female stated that she decided to volunteer to fly as an instructor at undergraduate pilot training (UPT) rather than accept another assignment flying fighter aircraft. UPT sorties are considerably shorter, and training aircraft have no ability to refuel in the air. Shorter missions, combined with lower performance aircraft, allow women to execute the vast majority of sorties without experiencing bladder discomfort.

\section{Piddle Packs}

The current primary manual method for male pilot relief during a sortie is the relief bag, also known as a "piddle pack" (Figure 7). The bag is made of a durable plastic with a flexible metal clasp positioned at the top, which is similar to a resealable sandwich bag. The bag has a throat that narrows from the top opening and widens as it approaches the main volume. Inside the throat is a flap/valve that reduces leakage throughout the rest of the flight, assuming the bag stays right side up throughout the flight. 


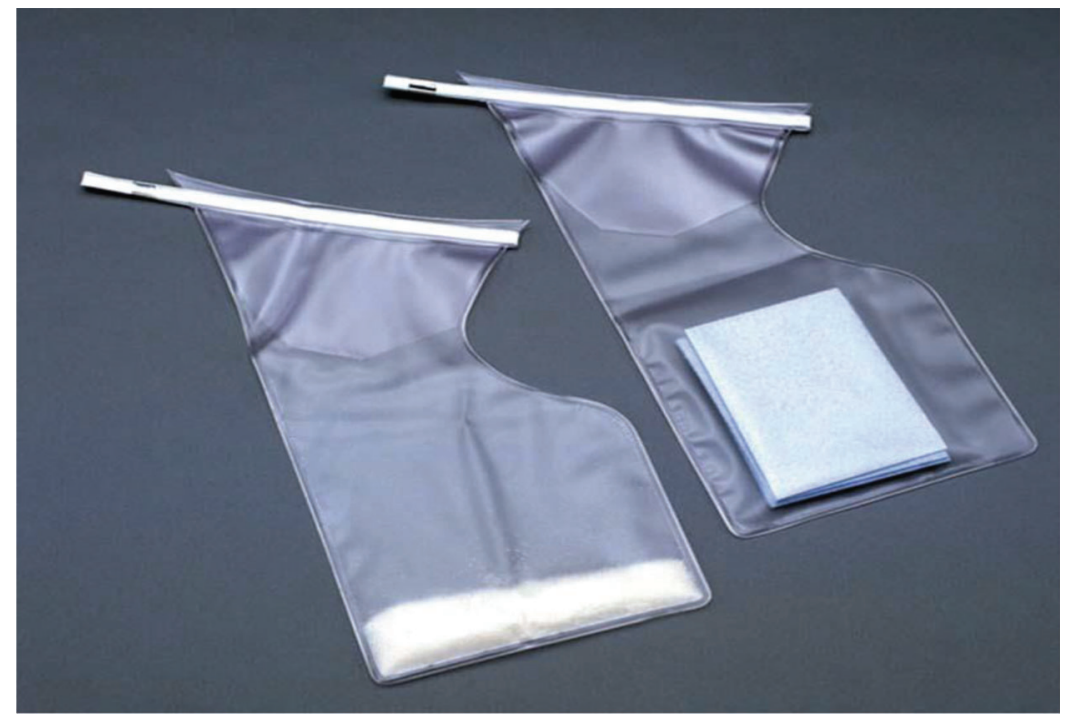

Figure 7. Piddle pack. (2021. Ontime Supplies, https://www.ontimesupplies.com/lci800878-skilcraft-piddle-pak-crew-relief-bag-16-91-fl-oz-vinyl.html. Reprinted with permission.)

There are two types of relief bags available to U.S. Air Force pilots. The first bag contains crystals in the main chamber that act similarly to a sponge. As they encounter liquid, they soak up the liquid forming a thick gel that diminishes the chance of leaks after the bag is sealed. The second type of relief bag contains a dehydrated, vacuumpacked sponge in the middle of the main containment chamber. As liquid encounters this sponge, the sponge expands, soaking up the liquid to better encompass the contents. These relief bags are common, and routinely used by male pilots. The design of the bag, however, as well as the differences in male and female anatomy result in bags that are less user friendly for female pilots.

As demonstrated in Figure 8, effective use of the bag requires the pilot to temporarily remove or loosen the lap belt, partially undress, and suspend their body above the seat.

\section{Female Relief System Designs}

It is well known that the urination process for females differs from males in that women must completely lower any undergarments that may block the urination path, and then strategically squat over a collection device for an effective voiding procedure to occur. The pelvic floor muscles relax, thereby reducing pressure on the urethra, which subsequently provides a complete and effective relief process. The ideal situation would be to limit any compression on the urethral sphincter that could result in an incomplete urination, or reduction in urine flow. Either of these results could extend the time needed by the female pilot to complete the process. Several different manual designs have been submitted to deal with the containment issue facing female pilots using relief systems. The Lady-J (Figure 9) was designed by U.S. Air Force flight surgeons and physiologists that market it, based on the ability of the device to contain $99 \%$ of the urine (Bisson \& Delger, 1993). Similar to the male piddle pack, the Lady-J has an anti-leak design and can be stored in the cockpit for the remainder of the flight.

The Lady-J shown in Figure 9 (Lady J Adapter, 2017) is very similar to the GoGirl diagram in Figure 10, which is a device marketed for use in controlled environments such as public bathrooms (Callaghan, 2018).

The Go-Girl Urination Director (Figure 10) directs the flow of urine into a collection device such as the Hollister Collection Device shown in Figure 11.

These relief systems include a specially formed rubber and foam "mask" at the top of the unit to better match women's anatomy and contain the greatest amount of urine. This problem is more prominent for female pilots as the mask must catch the urine, then direct and guide it into a collection device; whereas males use a relief bag that collects the urine as it exits the penis.

Accessibility is challenging for pilots in single-seat aircraft, since these fighter aircraft have very cramped cockpits with minimal room for movement. Most fighter aircraft have horizontal seats with a vertical back rest making this possible, although with significant effort. When using relief bags, male pilots are required to unzip the flight suit, remove any safety gear impeding the effort, and then raise the seat or prop themselves up to allow the urine to simply run into the bag. Female pilots face the same issues, but their anatomy drastically intensifies the difficulty. Female pilots must wear a flight suit modified with a zipper extending under the crotch approximately 12 inches further than a male flight suit (Air Combat Command, 2005). Females must also unbuckle from the ejection seat, squat in the seat, and hold any modified system in position while urinating. The collection unit must be raised 


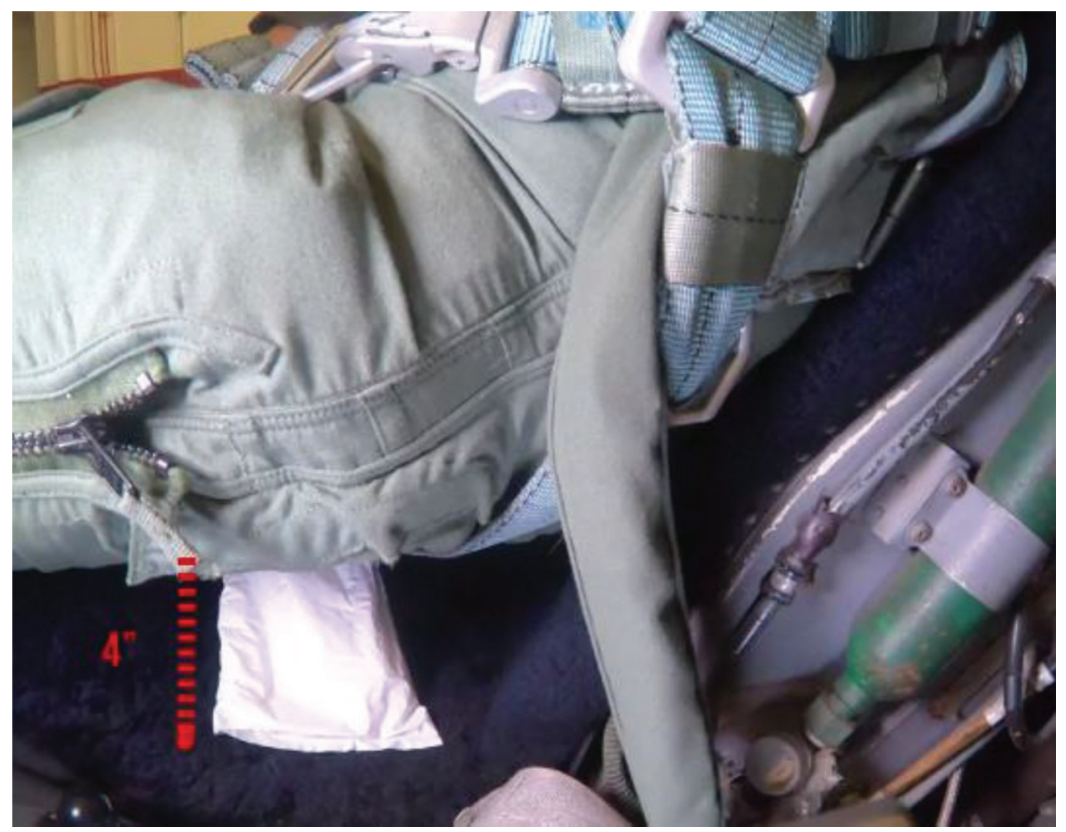

Figure 8. A female aviator demonstrates proper usage of a "piddle pack" for Military Times ("Here's How Female Aviators," n.d.).

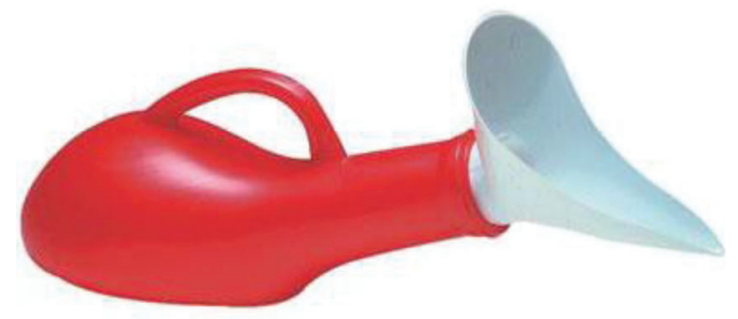

Figure 9. Lady-J. Shown with Little John urinary collection device. (Sporty's Pilot Shop, Lady-J Adapter, 2017, http://www.sportys.com/ pilotshop/safety-and-survival/other/lady-j-adapter-for-little-john-pilot-uri nal.html. Reprinted with permission.)

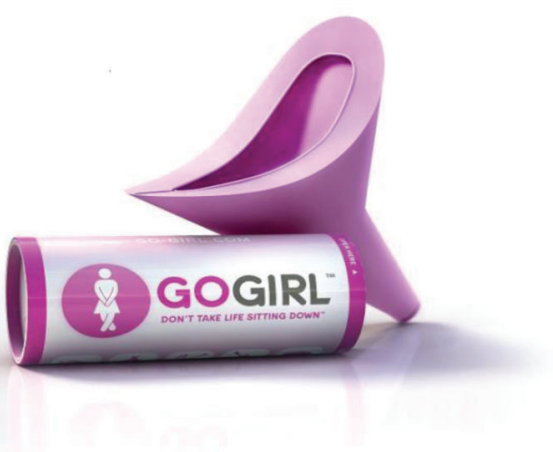

Figure 10. GoGirl urine collector. (GoGirl.com (2021). Reprinted with permission.)

higher than the bag to allow the urine to run down the collection tube without backing up or pinching the tube, which can cause an overflow and a pool of urine in and under the seat (Bisson \& Delger, 1993).

Many options have been considered to mitigate the problems of containment and accessibility, but the third

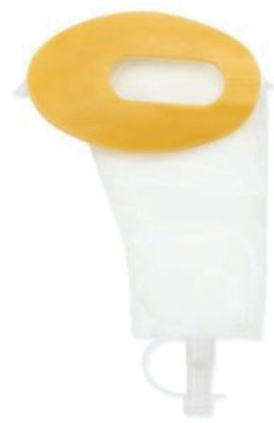

Figure 11. Hollister female urinary external collection device. (2017, https://www.hollister.com/en/products/continence-care-products/urine-col lectors/urine-collection-accessories/female-urinary-pouch-external-collec tion-device. Reprinted with permission.)

challenge, time, is undoubtedly the most difficult one. Most training or combat sorties have minimal nondemanding portions of the flight, and these time segments are primarily applied to cruising between the training airspace or combat Area of Responsibility. Fighter aircraft are typically deployed in training areas that minimize these time segments in order to maximize the use of fuel for weapons and tactics training.

Deployment missions, ferrying aircraft, or long crosscountry flights may offer some non-demanding flying, but may still be insufficient to complete the entire relief process. For example, one female pilot indicated that she required 10-15 minutes to fully unstrap, squat in the seat, and position the collection device. Unfortunately, the actual process of urinating is often slow, involving the release of small amounts of urine, checking the aircraft flight attitude, ensuring a flow into the containment bag, rechecking the collection mask, and repeating the steps. The entire process 
took her over 45 minutes. For transoceanic missions, fighters must maintain artificially high fuel levels to allow for diverts in the event of a fuel transfer malfunction. In this particular sortie, the female pilot was required to refuel every 30-45 minutes for the majority of the flight. Instead of repositioning and refastening her safety equipment, she remained unstrapped during two refuelings in order to completely empty her bladder. Female pilots must contort their bodies to allow them to reach under the crotch to hold the collection kit in place while urinating, and still monitor the aircraft to be in a refueling position if necessary. The obvious safety concern associated with discomfort is significant in that she specified that it was very difficult to fly and refuel due to her extreme bladder discomfort. This problem is complicated significantly if the sortie requires an exposure suit.

\section{Diapers}

Many female pilots have experimented with newer manual collection systems and found them to be impractical for most missions (Bisson \& Delger, 1993). Despite the shortcomings of these systems, pilots continue to fly longer missions and these missions require them to deal with the physiological challenges of waste management. As previously discussed, many female pilots resort to alternate methods to accomplish these longer sorties (Webster, 2003).

The U-2 has been operating extended missions since the inception of the aircraft 50 years ago. The extremely high altitude of U-2 missions necessitated a pressure suit to address the needs of both male and female pilots to complete urinary relief during flights. Men were fitted with a relief valve that flowed into a collection tube, very similar to the piddle packs used in fighters. The system is cumbersome and time consuming, but useable with little mission degradation. The solution for the female anatomy was a diaper system designed to collect and contain urine for the remainder of the flight.

Theoretically, other than the discomfort for the pilots sitting in slightly wet diapers for hours, this system appears to mitigate safety concerns allowing pilots to successfully relieve themselves and continue the mission. Female fighter pilots who have tried this system provided resounding feedback questioning the practicality of the diaper, primarily focusing on containment concerns. Contrary to U-2 sorties with severe leaks during maneuvers, the majority of fighter training missions require threat reactions that place the aircraft and pilot under several G's to safely maneuver into a position to employ ordinance. Additionally, while U-2 pilots wear self-contained pressure suits during flight and change once they exit the aircraft, fighter pilots wear the same flight suit for the remainder of the day, or must bring a separate flight suit to wear when a leak occurs and soils the suit. While soiled flight suits can be a source of embarrassment on the flight line, leaks in a fighter cockpit can contaminate the ejection seat, potentially leaking into wire bundles, computer casings, and displays. The lack of containment makes the diaper impractical for everyday missions directing female pilots to seek alternatives.

\section{Catheters}

Another solution available to female pilots is a bladder catheter, which is a tube inserted into the urethra allowing the bladder to drain through the tube and is subsequently connected to a modified relief bag (Figure 12).

The advantage of the catheter is that female pilots will be able to insert this device before any flight, and avoid worrying about urinary relief throughout the flight. After the flight, pilots would just have to dispose of the bag and remove the catheter. There are drawbacks to the catheter being used effectively as a practical option for daily training sorties, since inserting the catheter is challenging

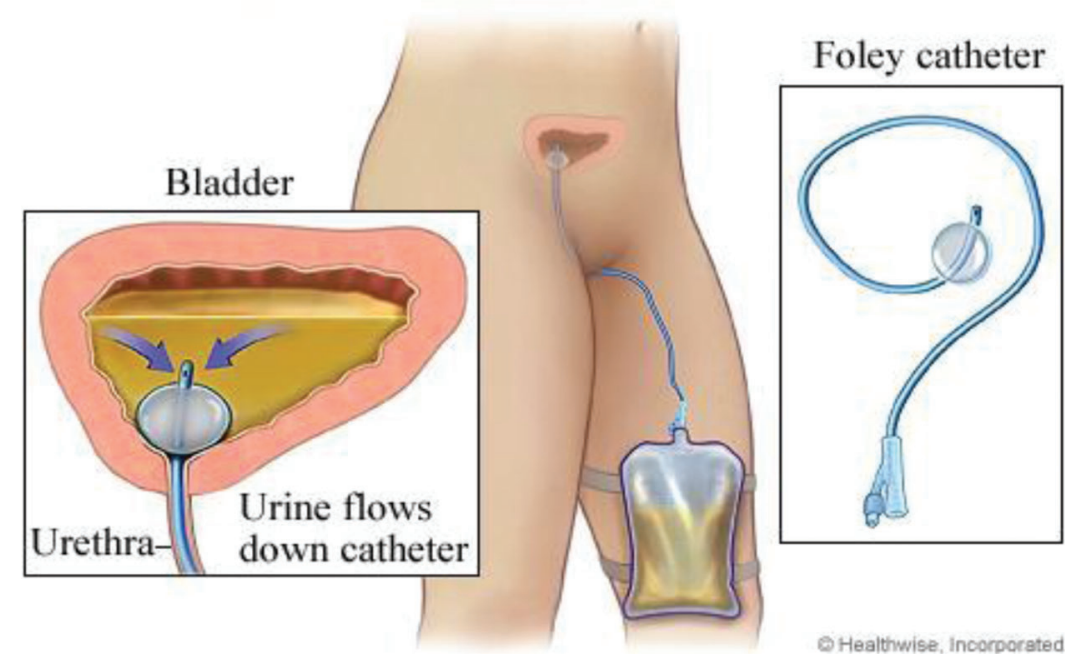

Figure 12. Indwelling Foley catheter for women. (2021. ๑ Healthwise, Incorporated. www.healthwise.org. Reprinted with permission.) 
and would require personal training or a medical technician to be in the squadron prior to every female sortie. For some female pilots, the need to constantly insert a catheter to perform flight duties may feel invasive, especially when compared to the less invasive methods for relief available to male pilots. This feeling can be detrimental to morale, and subsequently to readiness.

The catheter also exposes women to an increased risk of urinary tract infections and bladder infections. Catheter retention, in which the catheter's internal balloon cannot be deflated and the catheter cannot be removed, occurs in hospitals (Mishra, 2016). High-altitude fighter jets are very different from hospital settings, and minimal research has been performed on this device in flight crews. The effects of drastic altitude changes typically encountered in fighter/ attack sorties on the catheter are unknown.

\section{Specific Operational Concerns}

\section{F-35}

The F-35 is equipped with a US16E Martin Baker ejection seat, which has a different configuration from the legacy ejection seat and pilot flight equipment used in other fighter aircraft (Ejection Seat for F-35, n.d.). The legacy fighter pilot wears a harness that connects to both the survival kit and parachute. The pilot is held to the seat using a lap belt (Krock, 2007). The F-35 pilot does not wear an external harness, but buckles directly to the seat pan of the ejection seat. The lap belts and shoulder harnesses connect directly to a center buckle between the pilot's legs, providing the pilot with a single buckle to disconnect from the seat as shown in Figure 13.

This configuration that has the pilot connected to the seat pan rather than an external harness creates a problem in that the center buckle interferes with movement for both male and female pilots. However, the use of a piddle pack or Lady-J would require even more effort to completely unbuckle from the seat, unlike the legacy seats (ACES II) where the pilot remained connected to the parachute (even when disconnected from the lap belt). In the F-35 seat they would be disconnecting the strap between the legs, which connects to the seat pan and parachute, while trying to complete a urinary relief process.

Once unstrapped, unzipped, and when all undergarments are removed, female pilots must adjust so they can squat in the seat during flight to work through a relief process (refer to Figure 16). This position is physically challenging to achieve in small fighter cockpits, requiring the pilot to remove his or her hands and attention from the flight controls, and rely on autopilot. Although all pilots endure flight risks during this relief process, the anatomy of the female pilot adds to the convolutions required throughout the process. This process is complicated and can only be accomplished during lengthy, nondemanding portions of flight.

\section{Costs Associated with Redeveloping Ejection Seats}

The number of female fighter pilots in the military services is projected to increase. Both the Navy and Air Force are striving to effectively alleviate the relief issues facing all pilots. The Lady-J or GoGirl system has been implemented under the Aircrew Bladder Relief Device program (Air Combat Command, 2005). At the same time, the USAF implemented a new developmental program for a semiautomatic/automatic aircrew urinary bladder relief system.

Another possible solution might include an ejection seat with an integrated containment system to accommodate both genders. Integrating this solution in current fighters would be both expensive and time consuming. Designing, building, testing, and retrofitting the entire fighter inventory to accommodate human factors would take years and

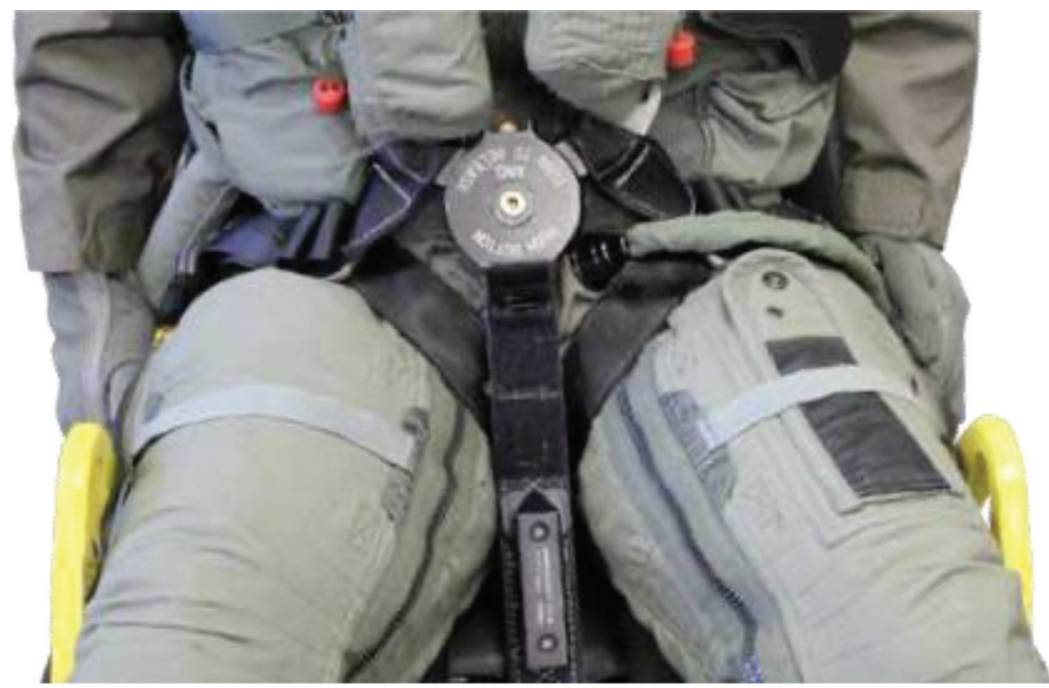

Figure 13. Pilot strapped into an F-35 Martin Baker US16E ejection seat. (Omni Medical Systems photo, http://omnimedicalsys.com/uploads/ AMXDLeaflet_sep2015.pdf) 
a large financial investment stretching beyond current budget parameters.

\section{Vacuum Assisted Relief System}

With more females in Air Force cockpits, the U.S. Air Force Life Cycle Management Center's Human Systems Division has experimented with numerous devices for both male and female pilots (U.S. Air Force Life Cycle, n.d.). The Vacuum Assisted Relief System is an aircrew bladder relief system that allows the pilot, whether male or female, to urinate in flight with comfort and convenience (Figure 14).

Three principal parts to the system include a pump, garment, and the receiver. A pump and battery pack may be mounted in a breast pocket or attached to a torso harness at breast level. Locating the pump at a level higher than the garment ensures little or no "leak back" to the garment. A garment worn like a diaper or underwear includes an intake manifold comprised of a number of perforated tubes sandwiched between layers of material. Urine is collected in the garment and drawn into the manifold tubes through these holes by means of vacuum from the pump. Collected urine then passes through a hose into a containment bag

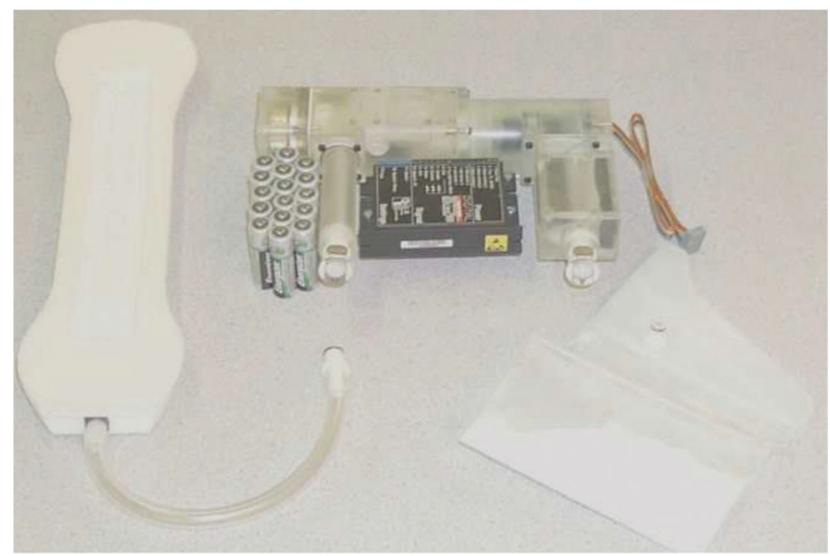

Figure 14. Advanced Mission Extender Phase 1. U.S. Patent 7018366, 2006. (Adapted from Vacuum Assisted Relief System (2006), http:// www.freepatentsonline.com/7018366.html) or receiver (Automatic Bladder, 2004; Automatic SelfCleaning, 2006).

\section{Advanced Mission Extender Device (AMXD)}

With more females flying fighter jets than ever, the U.S. Air Force Research Laboratory has experimented with numerous devices for both male and female pilots. The Air Force solicited proposals from private industry for solutions to in-flight bladder relief. Of the respondents, only one met all the Air Force's requirements. Developed by Omni Medical Systems, the solicitation resulted in the Advanced Mission Extender Device, or AMXD, which received FDA approval and Air Force Safe-to-Fly certification in 2006 (Omni Defense Tech, 2021).

The first generation AMXD ("Gen I") was tested in U.S. Air Force service, the U.S. Navy, and the Air National Guard for over four years (Figure 15).

This unit, usually strapped to the pilot's leg above the knee (Figure 16), was manually activated, per air force specifications, requiring the pilot to activate it when urination was necessary. The system was equipped prior to flight and did not require the pilot to remove any clothes, uncouple a harness or any other equipment, or disengage from the ejection seat, which made it a significant advancement over legacy relief products.

\section{AMXDmax (name changed to Skydrate in December 2021)}

In 2012, the U.S. Navy and U.S. Air Force jointly funded the development of the second generation AMXD ("Gen II," also known as AMXDmax; Figure 17).

The AMXDmax is a quarter of the size and weight of the previous generation device. Further development resulted in the optional Through Suit Connector (TSC; Figure 18), allowing the system to be used with immersion suits and CBRN ensembles The TSC expands the operational capabilities of the system, allowing it to be incorporated into PPE safety wear, cold weather gear, immersion suits, and other protective equipment.

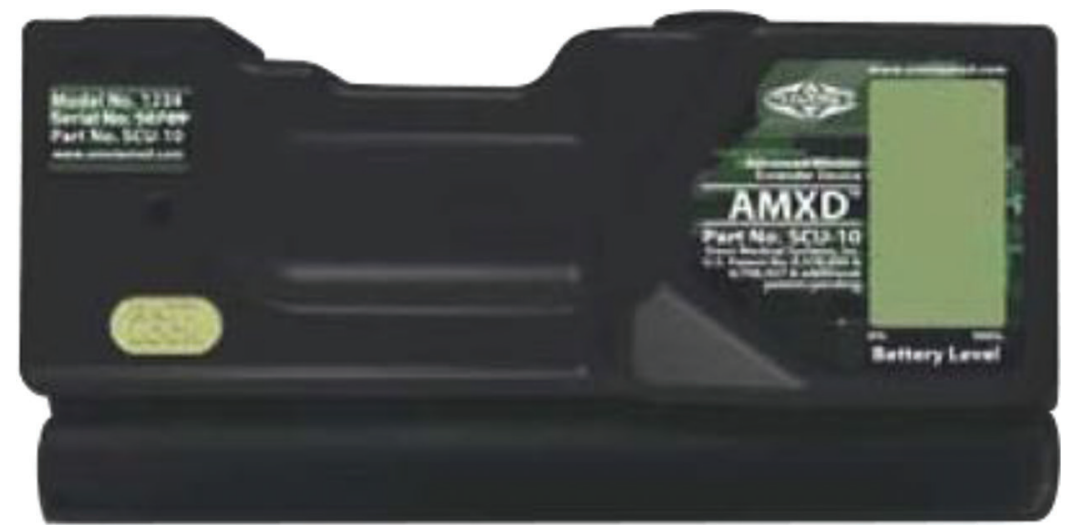

Figure 15. AMXD Gen I, fielded 2006. (Adapted from Omni Defense Tech, 2021. https://www.omni-Defense.com/?page5products\%29=). 


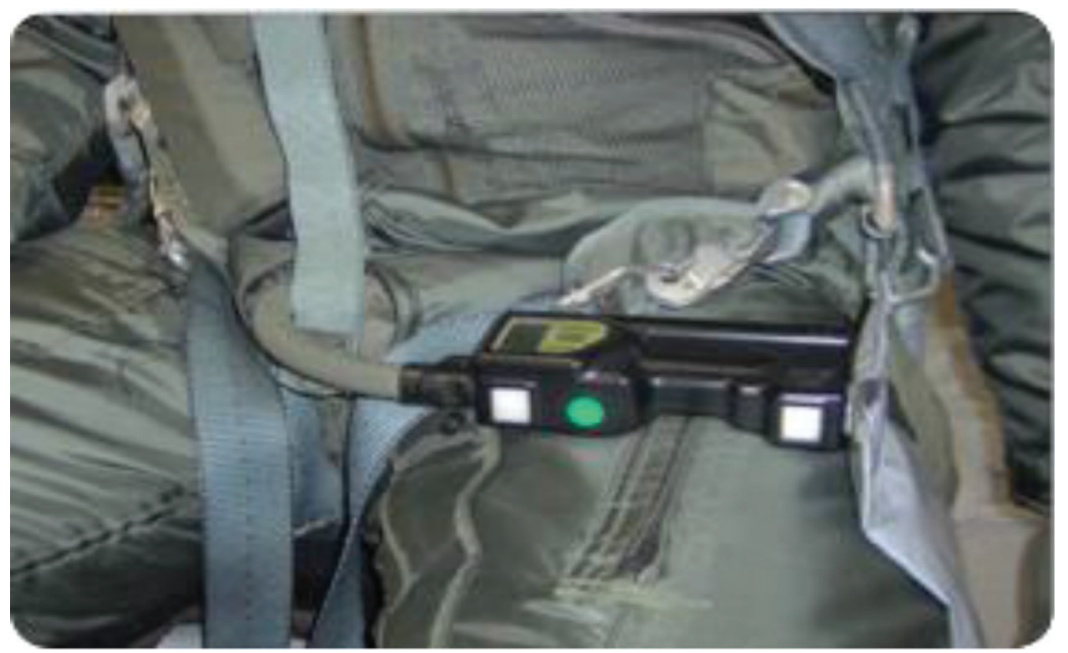

Figure 16. Advanced Mission Extender Device (AMXD). (Adapted from Omni Medical Systems, 2015, https://www.omnimedicalsys.com/ index.php?page $=$ products)

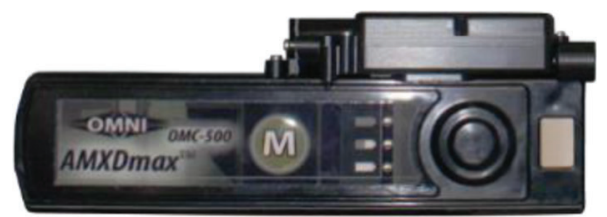

Figure 17. AMXDmax Gen II, fielded 2014 (Harvie, 2016). (Adapted from Omni Medical Systems, 2021.)

The AMXDmax is fully automated and designed for use in both fixed and rotary wing aircraft. The device is equipped with sensors in the collection cup (for males) or collection pad (for females) that automatically engage the urine evacuation system, moving the urine to the storage bag (Figure 19). The process is hands-free and operates effectively for high-performance aircraft at all altitudes. It received Safe-to-Fly certification for all U.S. military aircraft (except for the F-35) in 2014, and completed certification for the F-35 in 2018.

The AMXDmax is a more sophisticated piece of equipment than its predecessors and is a long way from the horn and valve systems that were so prevalent in the twentieth century. Like any piece of military equipment, proper training is required in the use of the device. Once trained, pilots report high levels of satisfaction with the device. Describing an event in which he used the AMXD max, a test pilot proclaimed that the device was a literal lifesaver: “...we were forced to fly [F-35s] over epic storms where refueling was in jeopardy due to the turbulence of Bomb Cyclone storms below us as we transited over the North Atlantic, Iceland and Greenland. The return mission was 13 hours in duration and involved 16 aerial refuelings. Again, there was no chance that our crews would have been able to relieve themselves by unstrapping and using a piddle pack. AMXDmax saved us."

The AMXDmax is certified Safe-to-Fly on the following USAF aircraft: F-22, F-35, F-16, F-15, A-10, F-4, B-1, B-2,
B-52, C-130 Series, C-135 Series, E-3 Series, E-4 Series, E-8 Series, C-12 Series, T-38, T-6, T-1, CV-22, HH-60, and UH-1. Test pilots have praised the AMXDmax, with Lt. Col. Elaine Bryant, deputy director of the Air Force Life Cycle Management Center's Human Systems Division, describing it as a "vast improvement" over legacy relief measures (Driscoll, 2019). As of 2021, the AMXDmax remains the only device of its kind in regular military operation, and the only one to meet all Department of Defense specifications for in-flight bladder relief and certified Safe-to-Fly. It is deployed by the U.S. Air Force, U.S. Navy, U.S. Marines, and many NATO nations, which ensures that at any given moment there is an AMXDmax in the skies. In 2016, a senior officer with the Royal Australian Air Force wrote that "...without the AMXDmax system extended missions simply could not have been completed [by female pilots]." A U.S. Air Force female fighter pilot wrote that the need to wear specialized gear while on deployment in Europe hampered her ability to relieve herself in flight; but with the AMXDmax, she flew over 330 hours: "[It] made a huge difference in my flying comfort and ability to fly these long missions... I believe it will be a standard life support system in [the] aviation world." Omni Medical Systems incorporates feedback from the pilots who use the AMXDmax around the world for continuous development of the system.

As part of the ongoing United States space program, Omni Medical Systems-in conjunction with the National Aeronautics and Space Administration, NASA - has developed urinary relief systems that operate effectively in more extreme conditions, like microgravity (Figure 21). A third generation ("Gen III") device is currently under development, due to Air Force and Navy contracts, and will incorporate features from recent technology breakthroughs to extend the operational capabilities of the system and allow for improved performance. 


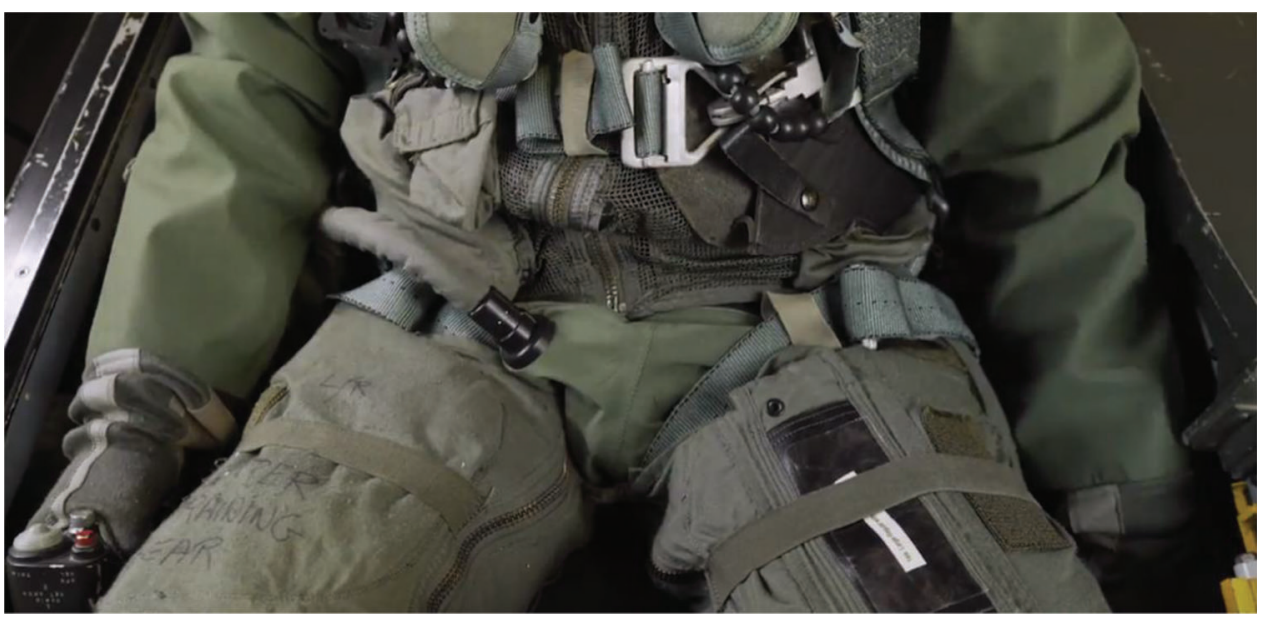

Figure 18. The Through Suit Connector on the AMXDmax, which allows for in-flight relief without removing the flight suit or any equipment (AMXDmax Through Suit Connector Demonstration, 2016). (Adapted from Omni Medical Systems, 2021.)
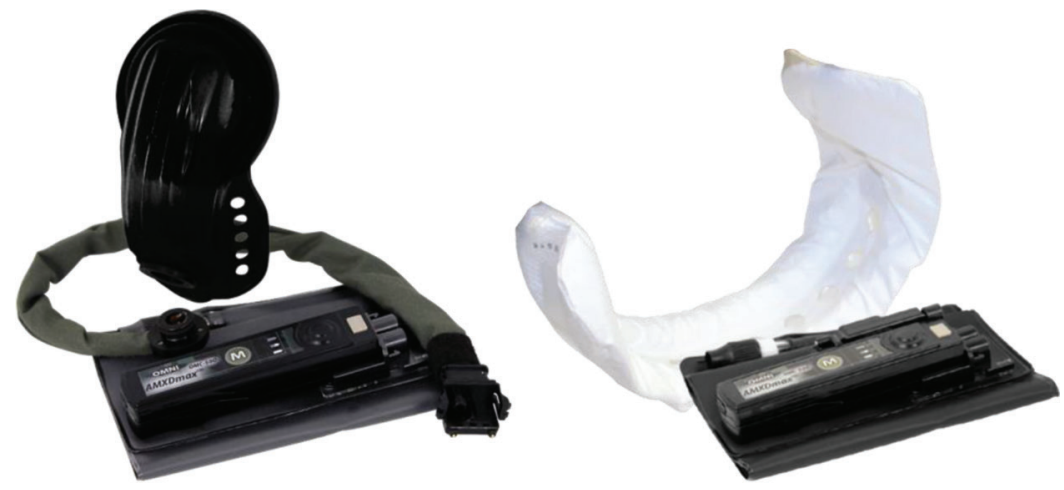

Figure 19. Male and female AMXDmax systems (Harvie, 2016).

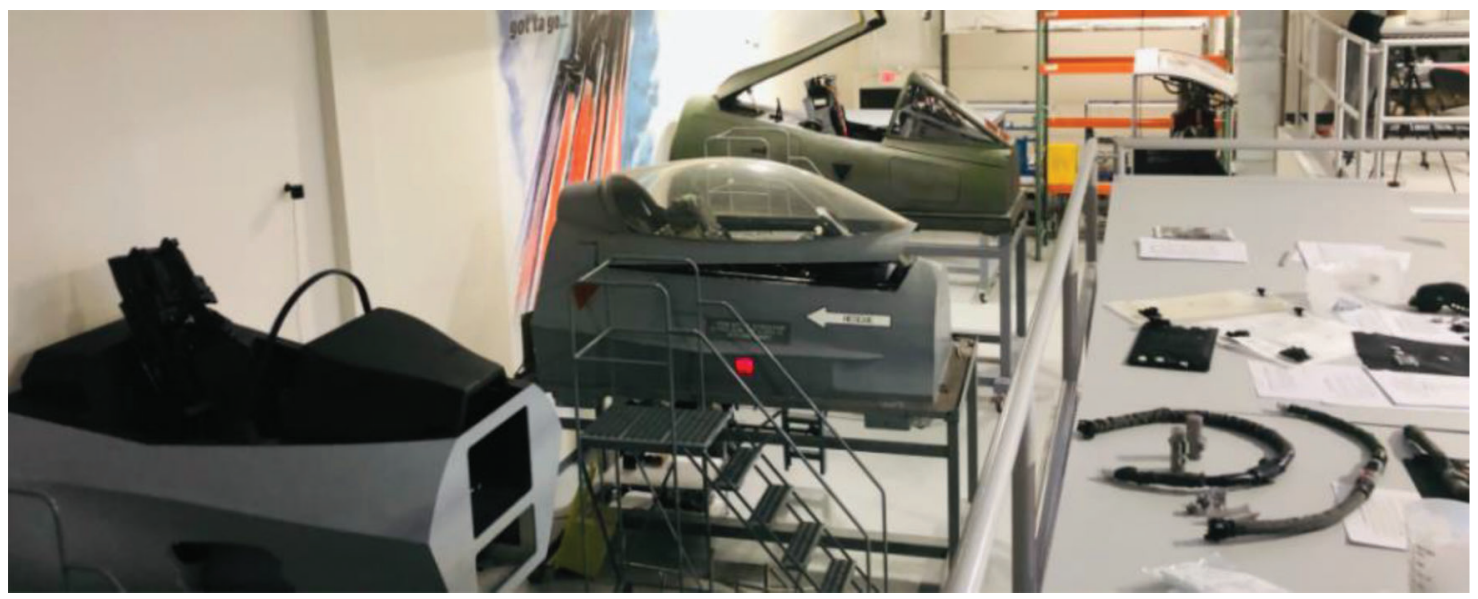

Figure 20. Omni's Training and Research Center. (2021. Omni Medical Systems photo.)

The AMXDmax is the lasting solution to the century-old dilemma of in-flight bladder relief, and Omni is continuing to innovate and keep solutions up to date with the newest technologies (Figure 20).

\section{Conclusions}

Of all the methods used by aircrew over the years, the AMXDmax system appears to be the only solution currently available that allows a pilot to remain fully hydrated, secured in the ejection seat and flight gear, and on-mission for the duration of a sortie.

Fighter/attack pilots will continue to be a significant part of both American and allied warfighting capability. It is imperative that the USA and allied nations maximize training and combat effectiveness for all pilots on all sorties. Longer, more complex missions, in remote sites of 


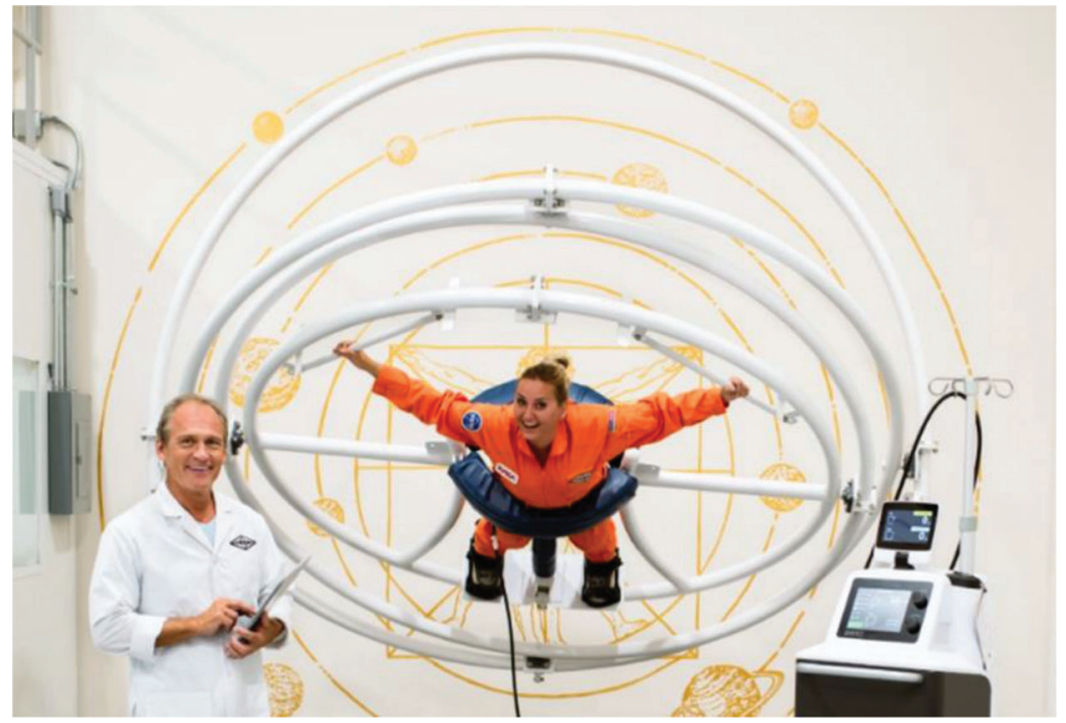

Figure 21. Omni NASA testing. (2021. Omni Medical Systems photo.)

the world challenge pilots managing the basic physiological needs of hydration and waste management. Education and training must be introduced during UPT as part of the core curriculum in order to foster adoption of effective bladder relief solutions.

Fielding and training of effective urine management systems will increase flight performance of pilots employing fighter/attack aircraft. The ongoing development of waste management systems in fighter aircraft to accommodate all gender types will ensure that the United States and its allies will continue to employ the most highly trained and prepared fighting forces in the world.

\section{Acknowledgments}

The authors wish to thank Air Force and Navy pilots who agreed to provide information for this research. Additionally, we would like to thank Omni Medical Systems for providing relevant photos and information on the AMDX.

\section{Author Background}

Dr. Marian Schultz is a tenured full professor at the University of West Florida. She holds a bachelor's degree from the University of Detroit/Mercy, a master's degree from Pepperdine University, and a doctorate from the University of Southern California. She has over 100 journal articles and presentations, and served as a consultant for Pace Foods, the 149th Fighter Wing at Kelly AFB, and conducted the United States Air Force Supervisory Workshops on Eglin AFB. One of her articles was published in the Spring 2004 edition of the Air and Space Power Journal.
Dr. James T. Schultz holds a bachelor's degree from Michigan State University, master's degrees from the University of Oklahoma and Embry-Riddle Aeronautical University, and a doctorate from the University of Southern California. He is a licensed pilot who spent 22 years in the U.S. Air Force, serving in numerous locations including Vietnam, Taiwan, and the Panama Canal Zone. While in the Air Force, he was assigned as the Base Commander at Bellows Air Force Base and Deputy Camp Commander at the Kilauea Military Camp, both located in Hawaii. He was also assigned to Headquarters, Strategic Air Command and the Air Force Military Personnel Center. He spent 26 years at Embry-Riddle Aeronautical retiring as the Dean of the College of Arts \& Sciences, and given Professor Emeritus status.

Joshua J. Schultz has a bachelor's degree from Spring Hill College, a master's degree in leadership from Embry Riddle Aeronautical University and another master's degree in human factors also from Embry Riddle Aeronautical University. He is currently a doctoral student in Aviation/ Human Factors at Capitol Technology University. He is Senior Associate Integration Test Engineer with L3/ HARRIS Technologies Corporation.

\section{References}

Air Combat Command. (2005, February). Bladder relief. Retrieved from https://www.sg.langley.af.mil/SGPF/FS-Toolkit/bladder\%20relief.htm

Air Force Life Cycle Management Center's Human Systems Division. (n.d.). Retrieved from https://www.wpafb.af.mil/News/Article-Display/ Article/1691140/aflcmc-provides-improved-bladder-relief-system-toaircrews/

AMXD user \& maintenance guide. (2007). Retrieved from http://www. omnimedicalsys.com/UserManual.pdf

Automatic Bladder Relief System. (2004). Free Patents Online. Retrieved from https://www.freepatentsonline.com/6706027.html 
Automatic Self-Cleaning Bladder Relief System. (2006). Patents. Google. Retrieved from http://patents.google. com/patent/US20040243075A1/ en

Bajak, F. (1993, October 28). Pilot's urgent need leads to air force fighter crash. Retrieved from https://apnews.com/article/9b5fe5b7cce0b0e4 1ad700718da756ba

Bisson, R., \& Delger, K. (1993, February 1). A prototype urine collection device for female aircrew. Retrieved from https://ntrs.nasa.gov/ citations/19940007077

Callaghan, A. (2018, June 6). The pee funnel is the secret superhero of women's gear. Outside Online. Retrieved from https://www. outsideonline.com/2311596/our-favorite-pee-funnels

Chandler, J. (1991, March 23). Air Force report concludes F-16 crashed after pilot tried to relieve himself. Los Angeles Times. Retrieved from https://www.latimes.com/archives/la-xpm-1991-03-23-me-542-story. html

Driscoll, K. (2019, February 1). Wright-Patt device improves bladder relief for fighter pilots. Dayton-Daily-News. Retrieved from https:// www.daytondailynews.com/business/wright-patt-device-improvesbladder-relief-for-fighter-pilots/O29bJL2vUxlDa9Mh7fZFOI/

Dugdale III, D. C. (2019, July 4). Urine 24-hour volume. MedlinePlus Medical Encyclopedia. Retrieved from https://medlineplus.gov/ency/ article/003425.htm

El-Sharkawy, A. M., Sahota, O., \& Lobo, D. N. (2015). Acute and chronic effects of hydration status on health. Nutrition Reviews, 73(suppl_2), 97-109. https://doi.org/10.1093/nutrit/nuv038

Harvie, M. (2016). Air Force-funded AMXDmax eliminates safety issues.

Here's how female aviators tackle the 'piddle pack'. (n.d.). Military Times. Retrieved from https://www.militarytimes.com/video/2020/03/ 02/heres-how-female-aviators-tackle-the-piddle-pack-newsbreak/

Krock, L. (2007, November). Outfitting a fighter pilot. NOVA. Retrieved from https://www.pbs.org/wgbh/nova/warplanes/pilo-nf.html

Lady J Adapter (for Little John Pilot Urinal). (n.d.). Retrieved from https://www.sportys.com/lady-j-adapter-for-little-john-pilot-urinal.html

Lindseth, P. D., Lindseth, G. N., Petros, T. V., Jensen, W. C., \& Caspers, J. (2013). Effects of hydration on cognitive function of pilots. Military Medicine, 178(7), 792-798. https://doi.org/10.7205/MILMED-D-1300013
Mishra, S. (2016). Tragedy of inappropriately managed Foley catheter. Journal of Obstetrics and Gynecology of India, 66(Suppl. 2), 679-682. https://doi.org/10.1007/s13224-016-0884-0

Mizokami, K. (2019, January 3). Having to pee at 30,000 feet is a serious problem. The Air Force has come up with an ingenious solution. Popular Mechanics. Retrieved from https://www.popularmechanics. com/military/aviation/a25736613/new-device-helps-fighter-pilots-peeat-30000-feet/

Mk16 Ejection Seat for F-35. (n.d.). Martin-Baker. Retrieved from https:// martin-baker.com/products/mk16-ejection-seat-f-35/

Omni Defense Tech. (2021). Never Unbuckle Again. Retrieved from https://www.omni-Defense.com/?page5products\%29=

Pilot's urgent need leads to Air Force fighter crash. (1993, October 28). AP News. Retrieved from https://apnews.com/article/ 9b5fe5b7cce0b0e41ad700718da756ba

Policy on the Collection and Analysis of Mishap Human Factors Data. (2005, May 10). Memorandum of agreement between Army Combat Readiness Center and Naval Safety Center and Headquarters, United States Marine Corps (Safety Division) and United States Coast Guard Health and Safety Directorate and Air Force Safety Center. Retrieved from https://www.safety.marines.mil/Portals/92/DoD\%20HFACS\% 20Taxonomy.pdf.

The possibility of G-induced loss of consciousness (G-Loc) during aerobatics in a light aircraft. (1988). No. 872-1017; p. 10 Department of Transport and Communications, Bureau of Air Safety Investigation. Retrieved from https://www.skybrary.aero/bookshelf/ books/2754.pdf

United States Air Force. (2014). Air Force pamphlet 11-419, 17 October 2014, Operations $G$ awareness for aircrew.

Verger, R. (2020, January 3). A pilot passed out while flying an F-15 over Oregon. Here's what happened next. Popular Science. Retrieved from https://www.popsci.com/story/technology/f-15-incident/

Webster, N. (2003). To pee, or not to pee... Female aviators face a dilemma. The Free Library. Retrieved from https://www.thefreelibrary. com/To+pee $\% 2 \mathrm{C}+$ or+not+to+pee+...+Female+aviators+face+a+dilem ma.-a0100172334

Werfelman, L. (2008, June). Dry and high. AeroSafety World, 44-47. 